\title{
FOUCAULT E O NASCIMENTO DO DISCURSO: O ENUNCIADO E O PODER
}

\author{
Tomás Prado \\ Universidade São Judas Tadeu/São Paulo
}

Resumo: $O$ artigo investiga uma ruptura no pensamento de Foucault e explicita as suas principais referências. Buscamos demonstrar que há dois entendimentos do conceito de arqueologia. 0 prisma de análise é a linguagem e, para compreendê-la, nos referimos às relações de Foucault com duas tradições, representadas por Heidegger e Wittgenstein. 0 trabalho investiga também de que forma o segundo campo da arqueologia, no qual as práticas discursivas tomam o lugar da experiência alegórica com a linguagem, ao privilegiar as descontinuidades no lugar da institucionalização dos seus usos correntes, significa uma elaboração original, onde encontramos a trama da linguagem, mais precisamente das práticas discursivas, com o poder.

Palavras-chave: Foucault, linguagem, discurso, enunciado, poder

\begin{abstract}
The paper investigates a rupture at Foucault's thought and clarifies its main references. We demonstrate that there are two understandings of the concept of archeology. The prism of analysis is the language, and to understand it, we refer to the relationship of Foucault with two traditions, represented by Heidegger and Wittgenstein. The paper also investigates how the second field of archeology, in which the discursive practices take the place of the allegorical experience with language, privileging the discontinuities instead of institutionalization of its current uses, means an original development, in which we find the plot of language, more precisely of discursive practices, with power.
\end{abstract}

Keywords: Foucault, language, discours, statement, power

\section{Dois campos da arqueologia}

Deleuze organiza os capítulos do seu livro Foucault em duas partes. A primeira se chama "Do arquivo ao diagrama", e a segunda, "Topologia: pensar de outra forma". Ambas se voltam ao que vem depois "do arquivo", 
ao que surge a partir de 1969, com A arqueologia do saber. Mas, se realizar uma topologia pressupõe "pensar de outra forma", não é preciso estabelecer de início a primeira forma para que se possa compreender o que há de diferente e de novo com o marco que se dá para lá "do arquivo"? Consideramos nesta investigação que não há uma unidade nas investigações arqueológicas de Foucault e que o prisma conceitual capaz de esclarecer suas diferenças é a linguagem, mais especificamente - conforme o termo utilizado pelo próprio Deleuze - por meio de uma "topologia" da linguagem.

O primeiro grande quadro do pensamento de Foucault perdura até por volta de 1967, um ano após a publicação de As palavras e as coisas, com a conferência "Nietzsche, Freud, Marx". Nela, Foucault apresenta duas concepções de linguagem:

- inicialmente, a suspeita de que a linguagem não diz exatamente o que ela diz. O sentido que se apreende, e que é imediatamente manifesto, é talvez, na realidade, apenas um sentido menor, que protege, restringe e, apesar de tudo, transmite outro sentido, sendo este, por sua vez, o sentido mais forte e o sentido "por baixo". É isso que os gregos chamavam de allegoria e hypinoïa.

- por outro lado, a linguagem faz nascer esta outra suspeita: que, de qualquer maneira, ela ultrapassa sua forma propriamente verbal, que há certamente no mundo outras coisas que falam e não são linguagem. Afinal, é possível que a natureza, o mar, o sussurro das árvores, os animais, os rostos, as máscaras, as facas cruzadas, tudo isso fale; talvez haja linguagem se articulando de uma maneira que não seria verbal. Isso seria, se vocês querem, muito grosseiramente, o semaïnon dos gregos (FOUCAULT, 2008, p. 40).

Na primeira, a concepção alegórica, que fala de um sentido "por baixo", que é também o "mais forte", encontramos tanto a linguagem confrontada pelas referências hegemônicas da tradição, pondo-se por baixo e revelando-se mais forte do que a razão e a loucura, o sonho, a história e a autoria, quanto confrontada pelo discurso, a ele também se opondo "por baixo" e com mais força. A concepção de Nietzsche, Freud e Marx como pensadores que dariam uma forma comum ao pensamento da modernidade, apresentada na conferência de 1967, pertence predominantemente à forma alegórica de linguagem, porque é situada como uma atividade exegética de 
pensamento, de interpretação, e que se contrapõe à anterior concepção metafísica de conhecimento, que ignora o primado da história.

Na segunda hipótese, a do semaïnon grego, não há nada mais "por baixo" que condicione o que está na superfície. Mas isso não implica necessariamente ouvir o mar e "o sussurro das árvores" - linguagem "não verbal". Será preciso ater-se à dimensão da empiria, da imanência, mas nos objetos que falam na mesma realidade que nós. É sobre essa virada, na qual um modelo alegórico de linguagem se torna um modelo imanente de discurso, que é possível projetar o surgimento da topologia "do arquivo", a qual se refere Deleuze.

Ainda em 1967, encontramos duas relevantes entrevistas, intituladas "A filosofia estruturalista permite diagnosticar o que é a atualidade" e "Sobre as maneiras de escrever a história". Entre as duas, algo de muito relevante acontece. Na primeira, admitindo os seus laços com o estruturalismo, Foucault afirma que possui com ele uma dupla relação, de distância e de proximidade ou "reduplicação": "De distância, já que falo dele em vez de praticá-lo diretamente, e de reduplicação, já que não quero falar dele sem falar sua linguagem." (FOUCAULT, 2008, p. 60). Este seria o primeiro sinal de um distanciamento, embora de um distanciamento que ainda não conseguiu encontrar outra linguagem.

$\mathrm{Na}$ segunda entrevista, algo novo surge. Foucault está discutindo as "maneiras de escrever a história", mas quando esperamos encontrar mais uma vez a referência ao estruturalismo, o que ele diz ao explicar o seu método de trabalho é: "esforcei-me para descrever os enunciados, grupos inteiros de enunciados, fazendo surgir as relações de implicação, de oposição, de exclusão, que podem ligá-los novamente." (Idem, p. 65). Embora essa explicação incida sobre os mesmos trabalhos, e incida em grande medida com pertinência, ela carrega um novo entendimento metodológico do que foi realizado. Não mais uma tarefa de decifração, de interpretação, o verbo norteador é "descrever". No lugar de "estrutura", surge a expressão "grupos de enunciados". No lugar de uma forma bicompartida, o que está "de baixo" e o que está na superfície, o que é condicionante e o que é condicionado, analisa-se agora "relações de implicação, de oposição, de exclusão". É certo que tais relações já existiam na investigação das rupturas entre uma epistémê e outra, mas antes se tratava de grandes quadros de pensamento, de ordens mudas e "códigos fundamentais", "códigos ordenadores", "primários", de uma "lei interior" e de uma "rede secreta" - terminologia muito marcante do prefácio de As palavras e as coisas. No lugar desses códigos obscuros, Foucault anuncia a imanência dos "enunciados", e então aquela segunda hipótese de tratamento 
da linguagem apresentada na conferência "Nietzsche, Freud, Marx", a do semaïnon, será desenvolvida.

Imaginamos que nela seja preciso identificar relações de similitude, de parentesco, de convenientia, aemulatio, analogia e simpatia, relações que não se dão mais, contudo, na linguagem das coisas, tal como encontrado na análise do Renascimento em As palavras e as coisas, mas sobre o arquivo, com os enunciados.

Meu objeto não é a linguagem, mas o arquivo, ou seja, a existência acumulada dos discursos. A arqueologia, tal como eu a entendo, não é parente nem da geologia (como análise dos subsolos), nem da genealogia (como descrição dos começos e das sucessões); ela é a análise do discurso em sua modalidade de arquivo. (FOUCAULT, 2008, p. 72).

Embora o trabalho que vemos surgir possa ser aplicado ao trabalho anterior, conferindo-lhe uma perspectiva alternativa a que já fora antes empregada pelo próprio autor, trata-se, fundamentalmente, de inaugurar um novo empreendimento. Foucault é radical em suas afirmações sobre seus trabalhos anteriores, refutando o que verdadeiramente fez, para abrir terreno para um novo trabalho. Um forte indício desta revisão consiste no fato de que ele tenha na época alterado substancialmente diversos livros anteriores, como Doença mental e psicologia, História da loucura e O nascimento da clínica. As referências teóricas que virão the auxiliar agora serão outras. Não mais Hölderlin e Heidegger, Lévi-Strauss e Lacan, Bachelard e Blanchot, toda a abordagem poética, fenomenológica, ontológica e estruturalista da linguagem. Veremos agora outro modo de formalismo, o da filosofia analítica.

Como justificar esse discurso sobre os discursos que eu mantenho? Que estatuto lhe dar? Começam-se, sobretudo do lado dos lógicos, alunos de Russel e de Wittgenstein a se dar conta de que a linguagem apenas poderia ser analisada em suas propriedades formais, desde que se leve em conta seu funcionamento concreto. A língua é um conjunto de estruturas, mas os discursos são unidades de funcionamento, e a análise da linguagem em sua totalidade não pode deixar de fazer face a essa exigência essencial (FOUCAULT, 2008, p. 73).

Um ano mais tarde, no verão de 1968, um grupo de pensadores reunidos sob a alcunha "O círculo de Epistemologia" e amparados, sobretudo, em uma questão formulada por Canguilhem a As palavras e as 
coisas, solicita esclarecimentos a Foucault. No lugar de defender as teorias presentes na obra de 1966, ele traz ideias e fala de conceitos inteiramente novos, até contrários ao que havia sido dito no primeiro momento. Ao falar do trabalho atual do historiador, ele afirma que "a atenção deslocou-se das vastas unidades formando 'época' ou 'século' para os fenômenos de ruptura” (FOUCAULT, 2008, p. 84). É certo que as rupturas e descontinuidades já lhe interessavam antes mesmo de As palavras e as coisas, mas ele considerava importante a diferença entre os séculos e, sobretudo, entre as épocas - o Renascimento, a "época clássica" e a modernidade.

A resposta ao círculo de epistemologia apresenta muitas passagens que serão aproveitadas posteriormente, em A arqueologia do saber. Guardaremos a análise dessas passagens para o momento em que elas encontram sua formulação mais completa e precisa, mas chamamos atenção a essa produção para que se constate que, em 1968, Foucault já pensa com um novo aparato teórico, o qual abrirá um campo de ideias novas. Uma passagem desse texto de 1968 parece particularmente digna da tarefa não só de delimitar esta topologia, que é, segundo Deleuze, "pensar de outra forma". É uma passagem que se despede da forma anterior:

Vê-se igualmente que essa descrição do discurso se opõe à análise do pensamento. (...) A análise do pensamento é sempre alegórica em relação ao discurso que ela utiliza. Sua questão é infalivelmente: o que, afinal, se dizia no que era dito? Mas a análise do discurso tem uma finalidade completamente diferente; trata-se de apreender o enunciado na estreiteza e na singularidade de seu acontecimento (FOUCAULT, 2008, p. 92).

\section{As duas tradições}

A introdução de A arqueologia do saber revela posições comuns ao método arqueológico de As palavras e as coisas, recusando também abordagens tradicionais da história. A primeira recusa incide sobre a visão linear e teleológica que, como se vê tanto em Kant quanto em Hegel, é uma marca da influência da filosofia sobre a história, do modo como a história foi submetida a um plano conceitual que pretendia dar-lhe um caráter científico, embora subtraindo o aspecto espontâneo e efêmero dos fatos empíricos. No lugar da tradição, e como modo de respeitar o que pode haver de abrupto nos acontecimentos, Foucault propõe que a análise histórica privilegie as rupturas: 
"A descontinuidade era o estigma da dispersão temporal que o historiador se encarregava de suprimir da história. Ela se tornou, agora, um dos elementos fundamentais da análise histórica" (FOUCAULT, 2008, p. 9). A segunda referência, que pode ser compreendida também como um desdobramento da primeira, é a crítica à primazia da subjetividade.

A história contínua é o correlato indispensável à função fundadora do sujeito: a garantia de que tudo o que lhe escapou poderá ser devolvido; a certeza de que o tempo nada dispersará sem reconstituí-lo em uma unidade recomposta: a promessa de que o sujeito poderá, um dia - sob a forma da consciência histórica -, se apropriar, novamente, de todas essas coisas mantidas a distância pela diferença, restaurar seu domínio sobre elas e encontrar o que se pode chamar sua morada (Idem, p. 14).

Da tentativa de engendrar um pensamento capaz de contornar tais influências, Foucault dedicara grande parte de seu trabalho até então à linguagem, buscando com ela empreender uma análise histórica capaz de contornar a dupla base sobre a qual se sustentou a tradição: a continuidade histórica e a primazia do sujeito. $\mathrm{O}$ que, entretanto, revela também uma diferença com relação a As palavras e as coisas é que a história não é mais mediada por uma experiência de linguagem. Se a raiz de sua preocupação em evitar o primado do sujeito e de assumir as vicissitudes históricas permanece presente, outro desenvolvimento será traçado. Até aquele momento, se havia um modo de reposicionar a história deslocando-a de um amparo na soberania do sujeito, na noção de que voluntariosamente o sujeito guia a sua história de acordo com o seu arbítrio, e então a linguagem viria interpor-se para revelar que ele sempre já atende a um apelo histórico uma vez que ela o atravessa e que ele não lhe escapa, agora a relação tripartida - história, linguagem e homem parece simplificar-se em uma relação direta entre a história e o sujeito, em favor da primeira e em detrimento do segundo. Em As palavras e as coisas, a grande impossibilidade de conciliação, o que seria monstruoso pensar, era um encontro do ser da linguagem com o ser do homem, mas agora a relação inconciliável é diretamente entre o homem e a história em sua realidade descontínua. $\mathrm{O}$ pensamento antropológico busca encontrar uma coerência, uma unidade, como forma de submetê-la e como um meio de salvar o homem da transitoriedade. Se em As palavras e as coisas o que estava em questão era a possibilidade do fim do homem em favor do ressurgimento do ser da linguagem, em $A$ arqueologia do saber Foucault considera que não há espólios recaindo sobre a morada soberana da linguagem, pois o que a história tem a revelar está resguardado simplesmente nos arquivos. 
Portanto, há pressupostos comuns: a crítica ao pensamento antropocêntrico, chamado em As palavras e as coisas de "duplo transcendental-empírico", e a crítica à visão continuísta da história, problemas que são como que duas formas de um mesmo. Mas não se fará mais uma enciclopédia da linguagem com base em seus marcos históricos, e cujos limites apontariam que é possível esperar, depois da época clássica, o retorno da linguagem do Renascimento na modernidade. Compreendidos tais pressupostos - fundamentais, pois o que será problematizado aqui é o nosso aprisionamento a uma filosofia que busca na linguagem condições mudas de possibilidade -, devemos partir em direção às especificidades de A arqueologia do Saber e, em especial, à posição que o discurso, profundamente resignificado, nela ocupa.

Desde o primeiro capítulo da obra de 1969, se tomamos como referência As palavras e as coisas, notamos que o discurso desloca-se, como já havia ocorrido nas entrevistas e conferências desse período, a uma posição de destaque. Em primeiro lugar, o discurso não será mais submetido a uma análise epistemológica; ele não serve mais, como na análise da época clássica em As palavras e as coisas, às representações. Se naquele momento as representações eram a fonte de clareza, o amparo seguro, o centro e o foco do modelo duplamente de linguagem e de conhecimento, deixando ao discurso a função de ser meramente o agente transmissor das representações de um espírito para outro, agora ele deve adquirir a plena predominância. Ele não requisitará nenhum amparo, mas bastará. $\mathrm{O}$ discurso é agora o princípio. $\mathrm{O}$ nascimento do discurso significa o modo como ele adquire no pensamento de Foucault um novo estatuto, com o poder de reorganizar todos os demais elementos que passarão a orbitá-lo.

Falar-se-á, em vez da relação do discurso com a linguagem e o conhecimento, de sua relação com a verdade - e negativamente. Não se pode esperar do discurso a revelação da verdade, na medida em que ele se sustenta sobre uma origem secreta inalcançável ${ }^{1}$. Em As palavras e as coisas, o a priori histórico "define as condições em que se pode sustentar sobre as coisas um discurso reconhecido como verdadeiro" (FOUCAULT, 2002, p. 219). Agora, Foucault abandona a busca de condições de possibilidade ocultas, de tramas misteriosas e, com elas, verdades ou fundamentos da verdade que deveriam repousar velados. Não se falará mais de investigar a "ordem muda" e a "rede secreta". Sendo "tão secreta e originária", ele afirma, da verdade "jamais

\footnotetext{
1 "Jamais seja possível assinalar, na ordem do discurso, a irrupção de um acontecimento verdadeiro; que além de qualquer começo aparente há sempre uma origem secreta - tão secreta e tão originária que dela jamais poderemos nos reapoderar inteiramente" (FOUCAULT, 2008, p. 27).
} 
poderemos nos reapoderar inteiramente" (Idem, p. 27). Em suma, "um discurso sem corpo, uma voz tão silenciosa quanto um sopro, uma escrita que não é senão o vazio de seu próprio rastro" (Idem, p. 28), todo o universo tímido que se buscou antes despertar, equivale aqui a um "jamais dito" (Idem).

Como respeitar, na nova conjuntura do discurso, o que havia de supostamente positivo no antigo projeto arqueológico, ou seja, a dedicação à existência muda da ordem? Se há qualquer coisa muda para a arqueologia que vemos renovar-se não se trata de algo que precisa de um substituto que lhe empreste uma voz, mas de algo que está mudo simplesmente porque foi esquecido e que, tão logo redescoberto, começará a falar. Não mais uma decifração, a projeção de uma coisa detrás de outra, a busca de algo extrínseco no que está acessível, mas simplesmente a recuperação do que foi renegado, a restituição do seu "status", a tarefa de descrevê-lo: "a história, em nossos dias, se volta para a arqueologia - para a descrição intrínseca do monumento.” (Idem, p. 8). E ainda:

É preciso estar pronto para acolher cada momento do discurso em sua irrupção de acontecimentos (...). Não é preciso remeter o discurso à longínqua presença da origem; é preciso tratá-lo no jogo de sua instância (Idem, p. 28).

Portanto, o tema da ordem muda e o da origem que sempre nos escapa quanto mais dela confiamos nos aproximar são relegados a um campo de análise impossível, que deve ser abandonado em favor da instância mesma do discurso, de sua imanência, de sua positividade.

A preocupação com a dimensão positiva do discurso estabelece uma aproximação com o positivismo lógico, sobretudo com a figura de Wittgenstein, a qual vemos bem representada pela seguinte aspiração encontrada em Investigações filosóficas:

Não queremos aprimorar ou completar o sistema de regras para o emprego de nossas palavras de maneira exorbitante. Pois a clareza a que aspiramos é, todavia, uma clareza completa. Mas isso significa que os problemas filosóficos devem desaparecer completamente. (WITTGENSTEIN, 1996, p. 76).

A linguagem, segundo Wittgenstein, funciona como um sistema de regras compartilhadas, sustentadas nas práticas existentes em uma comunidade linguística - práticas que ele denomina "jogos de linguagem". Assim, ele afirma: "Pergunta significativamente por uma denominação somente quem já sabe o que fazer com ela” (Idem, p. 32). 
Para Wittgenstein, a linguagem não é refém da subjetividade, da interioridade de cada um, das representações do espírito. Não importa a representação mental, porque sozinha ela pode se enganar, até que seja posta à prova nas práticas compartilhadas. $\mathrm{O}$ que vale é o domínio das regras que regem o uso, o qual só pode ser demonstrado e averiguado no próprio uso. O significado, segundo Wittgenstein, é a regra que rege o uso. Por isso, o uso não pode ser apenas um único caso, que não configuraria uma regra, já que poderia acontecer de haver uma adequação casual. Assim, o uso deve ser compreendido como um hábito, um costume, e as regras surgem da constante averiguação de um uso adequado ${ }^{2}$.

A linguagem, para Wittgenstein, obriga uma submissão espontânea dos indivíduos às práticas da comunidade: "Deixe que o uso lhe ensine o significado." (WITTGENSTEIN, 1996, p. 276). Com isso, ela está em uma posição, como vimos caracterizar a visão da linguagem para a modernidade, também profundamente oposta a uma noção de soberania na relações entre os indivíduos e a linguagem - característica, na visão de Foucault, da época clássica -, mas nem por isso se falará de uma experiência secreta. Ao contrário, tudo se passará no universo imanente, nas trocas, nos usos, nas "instituições". Portanto, não faz sentido falar em uma linguagem privada ou em significados dominados apenas por uma pessoa. Ele afirma: "Seguir uma regra é análogo a cumprir uma ordem. Treina-se para isso e reage-se à ordem de uma maneira determinada." (WITTGENSTEIN, 1996, p. 114). Ou ainda: "Se sigo a regra, não escolho. Sigo a regra cegamente" (Idem, p. 119).

No caso de Foucault, contra um pensamento exorbitante, o que deve desaparecer é a busca de uma origem aquém do discurso, não só quanto à representação, mas também quanto a toda experiência obscura com a linguagem. É o que ele dirá ainda na conferência pronunciada na PUC-Rio, em 1973, A verdade e as formas jurídicas:

Teria então chegado o momento de considerar esses fatos do discurso, não mais simplesmente sob seu aspecto linguístico, mas, de certa forma - e aqui me inspiro nas pesquisas realizadas pelos anglo-americanos - como jogos (games), jogos estratégicos de ação e reação, de pergunta e de resposta, de

\footnotetext{
2 "Não é possível um único homem ter seguido uma regra uma única vez. Não é possível uma única comunicação ter sido feita, uma única ordem ter sido dada ou entendida uma única vez, etc. - Seguir uma regra, fazer uma comunicação, dar uma ordem, jogar uma partida de xadrez, são hábitos (usos, instituições). (WITTGENSTEIN, 1996, p. 113).
} 
dominação e de esquiva, como também de luta (FOUCAULT, 2009, p. 9).

$\mathrm{O}$ que antes condizia, para o pensamento de Foucault, com a dimensão de mera superficialidade instrumental da linguagem aparece agora sendo não somente privilegiado em suas análises, mas assumido como dimensão única. O fato de que os homens não são senhores dos seus discursos não se dá em detrimento do discurso e em favor da origem secreta da linguagem. Discurso não é mais superfície de uma experiência profunda a ser conquistada; não é trazer à fala o fundamento. Ele é o que torna possível, no lugar de procurar verdades fundadas em um jamais dito, descrever e relacionar o que encontramos manifesto. Mais importante do que manter-se no campo das especulações, na busca por tramas ocultas, no pretenso resgate de origens sempre mais distantes conforme delas se aproxime, é descrever o que se manifesta historicamente no discurso.

Essa visão parece oposta à compreensão heideggeriana da linguagem que encontramos nos ensaios da década de 1950 e que marcaram Foucault ao longo da década seguinte. Devemos suspeitar de um rompimento com a visão heideggeriana de linguagem, na medida em que Foucault se coloca próximo agora dessa tradição distinta, principalmente de Wittgenstein ${ }^{3}$.

Em 1984, Foucault concede uma entrevista, posteriormente intitulada "O retorno da moral", em que afirma: "Heidegger sempre foi para mim o filósofo essencial. (...) Todo o meu futuro filosófico foi determinado por minha leitura de Heidegger.” (FOUCAULT, 2006, p. 259). Isso não significa, entretanto, que ele reproduza um pensamento anteriormente formulado ou que tenha permanecido sempre próximo ao filósofo alemão. O que comparece é o problema, certamente por abordagens bastante distintas. Se nos voltarmos para Ser e Tempo, percebemos que a linguagem e o discurso aparecem imbricados: "O fundamento ontológico-existencial da linguagem é o discurso" (HEIDEGGER, 2004, p. 219). Nessa abordagem, a linguagem reside naquilo que o discurso pronuncia, e não em uma autonomia secreta, como a pérola no fundo do mar hölderliano. Em Foucault, percebemos em A arqueologia do Saber que linguagem e discurso também parecem comprometer-se, pois o fundamento da linguagem é o

\footnotetext{
3 "Num mapa da filosofia os nomes de Heidegger e Wittgenstein ocupariam pontos extremos. Designariam sistemas opostos na constelação filosófica de nosso século. Seriam uma espécie de chavemestra para abrir uma compreensão em profundidade das reflexões de hoje" (CARNEIRO LEÃO, 1991, p. 134).
} 
discurso e não o inverso. Porém, há uma diferença significativa em relação àquilo que havia sido proposto por Heidegger, pois para o filósofo alemão, conforme é dito em Ser e Tempo, há uma "totalidade significativa" que "se estrutura na articulação do discurso". E essa totalidade significativa é a "compreensão" que sempre já se impõe à nossa presença no mundo; é o prisma por meio do qual o questionamos e que nos abrem as possibilidades de nossa existência, em suma, aquilo que nas décadas seguintes suplantará a figura do Dasein (ser-aí) em favor da esfera então nomeada linguagem algo que, na articulação foucaultiana, apareceria como uma ordem secreta com base na qual o discurso se forma -, consideração condizente com o plano de As palavras e as coisas, mas que fora também abandonada. Se há um elemento capaz de esclarecer essa ruptura no pensamento de Foucault é que não se poderá mais pressupor nenhuma experiência primitiva que corresponda ao que foi por Heidegger denominado "totalidade significativa". Foucault diz: "Nada seria mais falso do que ver na análise das formações discursivas uma tentativa de periodização totalitária: a partir de certo momento e por certo tempo, todo mundo pensaria da mesma forma, apesar das diferenças de superfície." (FOUCAULT, 2008, p. 167).

De fato, Heidegger afirma: "Discurso e escuta se fundam na compreensão. A compreensão não se origina de muitos discursos e nem de muito se ouvir por aí. Somente quem já compreendeu é que poderá escutar" (HEIDEGGER, 2004, p. 223). Quando se está em uma epistémê, herda-se uma compreensão, o que sugere uma aproximação de Foucault com as formas de eco que caracterizam a linguagem de Hölderlin a Heidegger. De todo modo, a maior aproximação entre os dois pensamentos se dá no diálogo entre as obras das décadas posteriores no trabalho de Heidegger como o conjunto de conferências reunidas sob o título A caminho da linguagem -, e os estudos da linguagem produzidos até As palavras e as coisas, de Foucault. Enquanto o pensamento de Heidegger se desenvolve no sentido de distinguir cada vez mais a linguagem do discurso em favor da primeira, o pensamento de Foucault passa nesta nova topologia a privilegiar a imanência do discurso.

Foucault, de modo mais pragmático ou positivista, já não vê melhor alternativa do que descrever minuciosamente o que as manifestações efetivas da linguagem, os enunciados, nos permitem analisar, até que os limites dos tempos sejam explicitados, oferecendo-nos a possibilidade do novo não como resgate das promessas malogradas do passado, mas como saturação das formas de pensamento de uma época.

Começa a revelar-se a dignidade do papel do discurso na modernidade. Se vemos ressurgir o modelo do Renascimento, cumpre 
respeitar a diferença de que a similitude não incidirá mais sobre as coisas, e sim sobre os enunciados. Se o pensamento de Foucault caminha em direção a uma filosofia da imanência, uma empiria sustentada em arquivos, é preciso reconhecer que se trata de uma imanência no campo do que é dito e não no campo das coisas ou objetos, como pretenderia o modelo do semaïnon, pois estes dependem dos discursos que sobre eles são projetados.

\section{Os modelos de trabalho}

Recordemo-nos da heterotopia de Borges. A "enciclopédia chinesa" é um conjunto de enunciados sobre os seres. Do riso que ela provoca, nasce As palavras e as coisas, livro no qual Foucault volta sua atenção para o espaço que permite reunir as palavras e as coisas, um espaço que deveria pré-existir, ser tomado como ponto de partida, porque, de acordo com um momento e um lugar determinados, essa reunião será ou não reconhecida será utópica, heterotópica ou atópica (afasia). Mais do que os enunciados, Foucault buscou decifrar esses espaços históricos de acolhida, as condições de possibilidade para a experiência, ou seja, o modo como sobre um mesmo conjunto é possível incidir diferentes familiaridades. Mas agora ele nos diz algo diferente: "Tentei descrever relações entre enunciados" (FOUCAULT, 2008, p. 35). O que há de novo é que o espaço não mais preexiste aos enunciados, não os condiciona, mas será determinado por eles. Não se trata mais da possibilidade de conferir diversas interpretações a um mesmo conjunto, mas de determiná-lo por sua realidade interna, pelo modo como ele mesmo se afirma e que nos constrange a aceitá-lo.

Analisadas as relações de A arqueologia do saber com os estudos anteriores de Foucault e com antigas e novas influências, é preciso retomar a questão: como entender a formação do discurso? Como reunir o seu conjunto? Voltamo-nos não para a sua condição de existência, mas para a sua unidade mínima.

De modo paradoxal, definir um conjunto de enunciados no que ele tem de individual consistiria em descrever a dispersão desses objetos, apreender todos os interstícios que os separam, medir as distâncias que reinam entre eles - em outras palavras, formular sua lei de repartição. (FOUCAULT, 2008, p. 37).

Não se busca mais reunir, da multiplicidade de abordagens, as disciplinas, as linguagens da ciência e das artes, os séculos ou as épocas, uma constelação de um mesmo objeto, por exemplo, em História da loucura, tudo o que foi dito sobre a loucura. É preciso agora deixar cada 
coisa em seu lugar: "O objeto que é colocado como seu correlato (da loucura) pelos enunciados médicos dos séculos XVII ou XVIII não é idêntico ao objeto que se delineia através das sentenças jurídicas ou das medidas policiais" (FOUCAULT, 2008, p. 36). No lugar de recompor uma unidade estranha e retratar a razão pelo viés desse estranhamento, deduzindo à distância a linguagem, abandona-se a grande constelação e busca-se, em vez disso, uma "lei de repartição". Despede-se das semelhanças e das identidades utópicas e atópicas, retirando-se das heterotopias as regras das quais elas não podem escapar. Teríamos três modelos: o de História da loucura, em que se coloca o objeto como articulador de um espaço múltiplo; o de As palavras e as coisas, no qual se coloca o espaço como condicionador de discursos sobre uma multiplicidade de objetos; e A arqueologia do saber, em que se coloca o discurso, um conjunto de enunciados, como delimitador do espaço de um objeto, de modo que é o discurso que pauta as transformações dos objetos e dos espaços, e então se terá, mais do que um objeto em formas múltiplas, distintos objetos em formas singulares.

No lugar de ordens secretas, os enunciados revelam acúmulos e raridades; regularidades que contrapõem espaços de dispersão. Foucault busca, em suas próprias palavras, "fazer uma história dos objetos discursivos que não os enterre na profundidade comum de um solo originário, mas que desenvolva o nexo das regularidades que regem sua dispersão" (FOUCAUT, 2008, p. 53). Quando identificamos determinado acúmulo de enunciados aparentados, identificamos a emergência de uma positividade. Não mais um estruturalista, alguém que pressupõe que os enunciados surgem atendendo a uma estrutura previamente existente, um esqueleto formal que se repete com diferentes superfícies, ele agora se declara um positivista, porque, em vez de decifrar estruturas, irá "descrever relações de exterioridade"4.

Por meio do processo comparativo de densidades, da busca pelos "nexos" na "exterioridade", não as reduzimos a igualdades, mas apontamos suas diferenças: "A comparação arqueológica não tem um efeito unificador, mas multiplicador." (FOUCAULT, 2008, p. 180). Se o modelo do Renascimento é insuficiente para esclarecer a relação dos enunciados no elemento do arquivo é porque será privilegiada mais a dispersão, a diferença, do que a semelhança. Em suma, a análise enunciativa, mais do

\footnotetext{
4 "Se substituir a busca das totalidades pela análise da raridade, o tema do fundamento transcendental pela descrição das relações de exterioridade, a busca da origem pela análise dos acúmulos, é ser positivista, pois bem, eu sou um positivista feliz, concordo facilmente" (FOUCAULT, 2008, p. 142).
} 
que à corrente de semelhanças ou ao espelhamento das identidades, que formam os acúmulos, se volta às raridades. Depois da análise dos objetos e das apropriações hegemônicas, depois da análise das estruturas, das ordens condicionantes, Foucault utilizará, para tratar dos mesmos interesses pelas experiências-limite, um trabalho sobre os discursos: "O termo discurso poderá ser fixado: conjunto de enunciados que se apoia em um mesmo sistema de formação; é assim que poderei falar do discurso clínico, do discurso econômico, do discurso da história natural, do discurso psiquiátrico" (Idem, p. 122).

Analisar enunciados não equivale a atender à normatividade gramatical ou aos preceitos lógicos, pois eles não residem nem no nível da frase - o campo semântico - nem no nível da proposição. Do contrário, em favor de aprisioná-los por novas estruturas, perderíamos a diferenciação singular que os constitui. Se determinarmos qualquer condição a priori para a formação de um conjunto de enunciados, inviabilizaremos a formação de uma regularidade própria na história. Mas isso não significa que não haja neles características intrínsecas. Em primeiro lugar, não há enunciado que não suponha outros; os enunciados devem associar-se a outros enunciados. Em segundo lugar, o suporte material também é determinante, pois se o suporte se modifica, seja uma conversa ou uma publicação, o enunciado também se modificará.

Embora possamos reconhecer que o enunciado seja o elemento mínimo que possibilita uma análise pela raridade e acúmulo, não se trata a rigor de uma unidade, mas principalmente de uma função.

Não há razão para espanto por não se ter podido encontrar para o enunciado critérios estruturais de unidade; é que ele não é em si mesmo uma unidade, mas sim uma função que cruza um domínio de estruturas e de unidades possíveis e que faz com que apareçam, com conteúdos concretos, no tempo e no espaço. (FOUCAULT, 2008, p. 98).

Mais do que a unidade formadora de um conjunto, o enunciado é uma função na medida em que ele distingue um conjunto de outro. $\mathrm{O}$ que Foucault propõe é que, sob os discursos, os enunciados não tenham uma realidade previamente condicionada. Torna-se necessário descrevê-los porque não se sabe previamente o que se encontrará, porque não se tem um espaço anterior o qual se possa inferir e no qual possamos inseri-los. Pela descrição, não encontramos a cada vez as mesmas características determinantes, mas a função que ali ocupam uns com os outros. Por isso, o 
espaço de encontro é o que os qualifica. É preciso considerá-los dentro de suas "séries".

\begin{abstract}
Não há enunciado em geral, enunciado livre, neutro e independente; mas sempre um enunciado fazendo parte de uma série ou de um conjunto, desempenhando um papel no meio dos outros, neles se apoiando e deles se distinguindo: ele se integra sempre em um jogo enunciativo, onde tem sua participação, por ligeira e ínfima que seja. (FOUCAULT, 2008, p. 112).
\end{abstract}

Como veremos agora, em vez de pensar essa função como uma relação de causalidade, cumpre estabelecer a relação do enunciado e do seu conjunto com as práticas de formação discursiva às quais eles pertencem. É esse jogo das relações dos enunciados entre si e com as suas práticas correspondentes que, finalmente, caracteriza o novo papel da arqueologia, o trabalho sobre os arquivos: "A arqueologia descreve os discursos como práticas específicas no elemento do arquivo." (FOUCAULT, 2008, p. 149). O novo papel da arqueologia é revelado, então, como o de encontrar nos arquivos os sistemas de enunciados que compõem formações discursivas e, com elas, como ainda veremos, as suas práticas correspondentes.

\title{
O estado civil da contradição
}

Descoberto o que há de próprio na análise dos enunciados, que é a investigação, por novos caminhos, do que estabelece limites, descontinuidades, do que compete a um discurso ou a outro, é preciso ver que uma dimensão à qual se conectam os enunciados irá adquirir um novo estatuto. É a esfera política. Desde História da loucura, a relação do saber e das instituições com a esfera política ocupa uma parte significativa das análises de Foucault, mas, na medida em que o ser da linguagem corria nos subterrâneos como a experiência fundamental, essa dimensão das decisões práticas, dos conflitos entre os homens, parecia condicionada, subordinada à atmosfera geral da linguagem. É como se os conflitos fossem predestinados a ocorrer por uma conjuntura mais ampla que carregasse a própria racionalidade dos homens. A relação entre o psiquiatra e o doente mental seria, nesse primeiro imaginário, senão uma herança do destino do ocidente, da ratio ocidental, da idade da técnica, então de uma época e a batalha contra tudo isso deveria ser travada também lá onde o pensamento recobraria uma experiência distinta dessas formas hegemônicas, na origem, onde recobraria uma alternativa a partir da qual colheríamos politicamente, 
quem sabe, em uma época distinta, alguns efeitos benéficos. Quando o discurso é alçado para a posição não mais de reflexo instrumental de uma experiência condicionante, mas para a imanência, com ele a dimensão política adquirirá também uma nova envergadura.

A arqueologia do Saber é a obra de Foucault que instaura a sua abordagem da linguagem na "evidência da linguagem efetiva" (FOUCAULT, 2008, p. 124), e esse evento abrirá para as suas investigações um novo campo: "Assim, o enunciado circula, serve, se esquiva, permite ou impede a realização de um desejo, é dócil ou rebelde a interesses, entra na ordem das contestações e das lutas, torna-se tema de apropriação ou de rivalidade." (FOUCAULT, 2008, p. 19).

É nesse ponto que se torna necessário pensar não só as proximidades de Foucault com o positivismo lógico, mas também as suas diferenças. $\mathrm{O}$ sistema de Wittgenstein é amparado no esclarecimento de regras que regem o discurso, regras que são explicitadas pelos limites que são revelados nos pontos em que fracassam. O filósofo austríaco afirma:

$\mathrm{O}$ fato fundamental é aqui: fixarmos regras, uma técnica, para um jogo, e então, ao seguirmos as regras, as coisas não funcionam tão bem como havíamos suposto; portanto, nós nos enleamos, por assim dizer, em nossas próprias regras. (...) $\mathrm{O}$ estado civil da contradição, ou o seu estado no mundo civil: este é o problema filosófico (WITTGENSTEIN, 1996, p. 74).

Foucault, de sua parte, assumirá não só o trabalho de reconhecimento das regras imanentes ao uso do discurso, como privilegiará também as diferenças, as faltas, a "contradição" ou, em sua terminologia, a “dispersão". Ele confrontará um jogo com outro. Ele reconhecerá as marcas do "estado civil da contradição" sobre o seu próprio discurso, sobre a pressão sofrida por todo escritor, sobretudo na filosofia, para que respeite as coerências, as regras uma vez estabelecidas em suas ideias. Ele defenderá o direito à contradição, à possibilidade de pensar com base em novas regras: "Vários, como eu, sem dúvida, escrevem para não ter mais um rosto. Não me pergunte quem sou e não me diga para permanecer o mesmo: é uma moral de estado civil; ela rege nossos papéis. Que ela nos deixe livres quando se trata de escrever" (FOUCAULT, 2008, p. 20).

O "estado civil da contradição" ao qual se refere Wittgenstein comparece no "estado civil" que "rege nossos papeis", ao qual se refere Foucault. Este reconheceu, já na conferência “O que é um autor?", de 1969, que esse "estado civil" está na base da função autor, a qual existe justamente como meio de garantir as coerências, as regras de enunciados 
que pertencem a uma mesma formação discursiva. A diferença entre os filósofos consiste em que, embora partindo de uma mesma dimensão de regras imanentes estabelecidas pelos usos que revelam contradições ou dispersões, Wittgenstein não revela particular interesse em analisar, nas práticas correspondentes aos discursos, a atuação do poder sobre as vidas, a transformação das instituições, a razão pela qual uma regra dá lugar a outra, enquanto para Foucault isso se transforma progressivamente no aspecto mais relevante das análises discursivas - o fato de que os discursos não estão sozinhos na imanência e que não basta reconhecer se eles funcionam ou não para o fim de permitir que os homens se compreendam. Há outras razões, que não o domínio das regras que regem o significado e o discurso outros domínios -, que fazem com que os homens historicamente não se compreendam.

Wittgenstein afirma: "A filosofia não deve, de forma alguma, tocar o uso real da linguagem; o que pode, enfim, é apenas descrevê-lo. Pois ela também não pode fundamentá-lo. Ela deixa tudo como é." (WITTGENSTEIN, 1996, p. 74). Para Foucault, a relação com a linguagem de descrição também é fundamental, mas o seu pensamento sobre como as coisas são não tem em vista deixar as coisas em seu estado, assim perpetuando-o, mas precisamente lembrar as diferenças e permitir que as coisas possam não ser mais como são. $O$ que se interpõe entre os dois filósofos é sobretudo a ocupação com a história, pois, se Wittgenstein se interessa pela clareza da linguagem instituída, Foucault se preocupa em que essa mesma clareza nas instituições não se naturalizem pela força do hábito como a única possível. Wittgenstein afirma:

A filosofia de fato simplesmente expõe tudo e não esclarece, nem deduz nada. Uma vez que tudo se encontra em aberto, não há também nada para esclarecer. Pois, o que porventura está oculto, não nos interessa.

Poder-se-ia chamar também "filosofia" o que é possível antes de todas as novas descobertas e invenções (WITTGENSTEIN, 1996, p. 75).

Se há algo oculto que ainda interessa a Foucault, não é o mesmo que um ocultismo, não significa uma experiência muda; deve aparecer no discurso embora não seja apenas discursivo. Falamos das práticas de poder. Ambos compartilham o interesse pela dimensão imanente do discurso, mas Wittgenstein não está preocupado em que as instituições nas quais os 
discursos se inscrevem possam ser reformadas e dar lugar a novos discursos. Se elas forem reformadas, o próprio uso dos jogos de linguagem revelará como se deve agir. Ele diz que devemos deixar que o uso nos oriente, que nos mostre os significados. Ele diz: "Compreender uma frase significa compreender uma língua. Compreender uma língua significa dominar uma técnica." (Idem, p. 113). Seu pensamento se dirige ao esclarecimento de um processo de aprendizagem; se volta a como podemos dominar as técnicas que estão a nossa volta. E Foucault, embora não queira prescrever novas técnicas e instituições melhores do que as atuais, quer que nos projetemos criticamente sobre os seus limites. No curso Em defesa da sociedade, possivelmente a obra em que melhor encontramos o esclarecimento de sua concepção do poder, ele afirma, a respeito das genealogias, que elas atuam "contra os efeitos centralizadores de poder que são vinculados à instituição e ao funcionamento de um discurso científico organizado no interior de uma sociedade como a nossa" (FOUCAULT, 2005, p. 14).

Mais uma vez, encontramos no interior de uma obra foucaultiana uma semente que abrirá ou aprofundará um novo campo de estudos. A temática do poder contraria diretamente o critério adotado para a análise dos discursos até então: a regularidade - na expressão do positivismo lógico, as práticas instituídas, compreendidas dentro da dimensão cotidiana. O que subtrai a linguagem de uma emergência espontânea própria e do movimento de sua institucionalização pelo torpor cotidiano é a emergência - ainda não sabemos se tão espontânea - do poder. Onde o poder atua, não há espaço para a regularidade, ou ainda, a regularidade deixa de ser o gênero que reúne raridade e acúmulo. Resta, então, somente raridade e acúmulo segundo emergências de poder.

Assim concebido, o discurso deixa de ser o que é para a atitude exegética: tesouro inesgotável de onde se podem tirar sempre novas riquezas, e a cada vez imprevisíveis; providência que sempre falou antecipadamente e que faz com que se ouça, quando se sabe escutar, oráculos retrospectivos; ele aparece como um bem - finito, limitado, desejável, útil - que tem suas regras de aparecimento e também suas condições de apropriação e de utilização; um bem que coloca, por conseguinte, desde sua existência (e não simplesmente em suas "aplicações práticas") a questão do poder; um bem que é, por natureza, objeto de uma luta, e de uma luta política (FOUCAULT, 2008, p. 137). 
No período que separa as entrevistas e conferências dos anos de 1967 e 1968 e a publicação de A arqueologia do Saber, mais especificamente da reflexão que é revelada, principalmente com base no conceito de "status" em "O que é um autor?", surge no pensamento de Foucault, e mais precisamente em seu pensamento dedicado à constituição dos discursos pelos enunciados no jogo da regularidade e da raridade, o problema do poder.

Ao assumir a cátedra no Collège de France em 1970, em sua primeira aula, posteriormente publicada com o título A ordem do discurso, Foucault sustenta que "o discurso não é simplesmente aquilo que traduz as lutas ou os sistemas de dominação, mas aquilo por que, pelo que se luta, o poder do qual nos queremos apoderar" (FOUCAULT, 2012, p. 10), e isso expressa, de modo tão abrangente quanto possível, o seu projeto para os próximos anos.

\section{Referências}

CARNEIRO LEÃO, E. Aprendendo a Pensar. Petrópolis: Editora Vozes, 1991.

DELEUZE, G. Foucault, Trad. Claudia Sant'anna Martins, São Paulo: Brasiliense, 2008.

FOUCAULT, M. "A filosofia estruturalista permite diagnosticar o que é a atualidade". In: Ditos e escritos, v. 2. Tradução Elisa Monteiro. Rio de Janeiro: Forense universitária, 2008.

. "Nietzsche, Freud, Marx". In: Ditos e escritos, v. 2. Tradução Elisa Monteiro. Rio de Janeiro: Forense universitária, 2008.

. "O retorno da moral" em Ditos e escritos, v. 5. Rio de Janeiro: Forense universitária, 2006.

"Sobre a arqueologia das ciências. Resposta ao Círculo de Epistemologia". In: Ditos e escritos, v. 2. Tradução Elisa Monteiro. Rio de Janeiro: Forense universitária, 2008.

. "Sobre as maneiras de escrever a história" em Ditos e escritos, v. 2. Tradução Elisa Monteiro, Rio de Janeiro: Forense universitária, 2008.

. A arqueologia do saber. Tradução L. F. B. Neves, Rio de Janeiro: Forense Universitária, 2008.

. As palavras e as coisas. Tradução. S. T. Muchail, São Paulo: Martins fontes, 2002.

. A verdade e as formas jurídicas. Tradução R. Machado e E. Jardim. Rio de Janeiro: NAU editora, 2009. 
A ordem do discurso. Tradução L. F. A. Sampaio, São Paulo: Edições Loyola, 2012.

. Em defesa da sociedade. Tradução M. E. Galvão, São Paulo: Martins Fontes, 2005.

HEIDEGGER, M. A caminho da Linguagem. Tradução M. S. C. Schuback. Petrópolis: Vozes, 2004.

. Ser e tempo. Tradução M. S. C. Schuback. Petrópolis: Vozes, 2000. WITTGENSTEIN, L. Investigações Filosóficas. Tradução M. Montagnolli, Petrópolis: Vozes, 1996. 